\title{
Fração total de células mononucleares intra-articular em cães submetidos à reconstrução do ligamento cruzado
}

\author{
[Total fraction of mononuclear intra-articular cells in dogs undergoing cruciate \\ ligament reconstruction] \\ D.C.M. Müller ${ }^{1}$, N.L. Pippi ${ }^{2}$, P.C. Basso ${ }^{3}$, L.V. Teixeira ${ }^{4}$, A.G. Sprada ${ }^{5}$, \\ D.L. Graça², S.T.A. Lopes ${ }^{2}$ \\ ${ }^{1}$ Universidade do Noroeste do Estado do Rio Grande do Sul (Unijuí) - Ijuí/RS \\ ${ }^{2}$ Universidade Federal de Santa Maria (UFSM) - Santa Maria, RS \\ ${ }^{3}$ Aluna de pós-graduação - Universidade Federal de Santa Maria - Santa Maria, RS \\ ${ }^{4}$ Aluna de pós-graduação - Universidade Federal do Rio Grande do Sul (UFRGS) - Porto Alegre, RS \\ ${ }^{5}$ Aluna de residência - Universidade Federal do Paraná (UFPR) - Curitiba, PR

\begin{abstract}
RESUMO
Avaliou-se a ação da fração total de células mononucleares autógenas da medula óssea (FCMO) por aplicação intra-articular, após a correção cirúrgica do ligamento cruzado rompido. Foram utilizados 20 cães, os quais sofreram desmotomia do ligamento cruzado cranial e caudal unilaterais, 21 dias antes do reparo cirúrgico. Dez animais receberam as células autógenas no momento da correção. As avaliações se deram por estudo radiográfico, exames clínicos e biópsias aos 50 e 90 dias pós-operatórios. O grupo que recebeu a FCMO apresentou crescimento ósseo intra-articular ao estudo radiográfico, contudo os 20 animais apresentaram células CD34 positivas em suas amostras biopsiadas, indicando haver presença de células-tronco em ambos os grupos. Conclui-se que, para o modelo experimental proposto, não se recomenda o uso da fração total de células mononucleares e que trabalhos experimentais com o uso de células-tronco nas articulações devem evitar modelos cujo foco de lesão mantenha contato direto com a medula óssea.
\end{abstract}

Palavras-chave: cão, células-tronco adultas, articulação, desmotomia

\begin{abstract}
This study was performed to evaluate the action of the fraction of total mononuclear cells from the bone marrow (FCMO) applied intra-articularly after the surgical repair of an experimentally ruptured cruciate ligament. Twenty dogs which suffered one-sided cruciate desmotomy of the cranial and caudal cruciate ligament 21 days before the correction were used. Ten animals received the FCMO at the time of correction. The assessments were done through X-ray and clinical examinations, and biopsies at 50 and 90 days postoperatively. It was concluded that there was no clinical difference between the two groups until 90 days of evaluation. The group that received FCMO grew intra-articular bone shown on the X-ray study. All twenty animals, however, presented cells marked with CD34 antibodies on their biopsy samples, indicating the presence of stem cells in both groups. It is concluded that for the experimental model, it is not recommended to use the mononuclear cell fraction, and in experimental studies with the use of stem cells in the joints models whose focus of injury keep direct contact with the bone marrow should be avoided.
\end{abstract}

Keywords: dog, adult stem cells, knee joint, desmotomy

Recebido em 30 de maio de 2011

Aceito em 26 de novembro de 2012

E-mail: cmdaniel@terra.com.br 


\section{INTRODUÇÃO}

A ruptura do ligamento cruzado (LC) é uma lesão diagnosticada em uma grande porcentagem dos cães com problemas articulares e também é causa importante de afecção da articulação femorotibiopatelar. O tratamento divide opiniões entre ser clínico ou cirúrgico. Alguns pesquisadores afirmam que não há técnica cirúrgica que estacione a progressão da afecção articular degenerativa. No entanto, o que se espera é que ocorra menor acometimento com a estabilização cirúrgica do que sem a intervenção (Brinker et al., 1999).

A utilização de células-tronco da medula óssea (MO) de indivíduos adultos abriu um novo horizonte na medicina reparadora, pois não há possibilidade de rejeição imunológica (já que as células são autólogas) nem a necessidade de estoque de células em bancos de tecidos, haja vista que o estoque aparentemente é inesgotável e ainda é possível expandi-las em cultura (Mota et al., 2005). Essas células possuem capacidade de se diferenciar de acordo com o meio ambiente local e migram sempre atraídas por fatores da inflamação aguda (Souza et al., 2005). Nos últimos anos, a utilização de células-tronco mediante o transplante da MO, tem se tornado comum (Gallacher et al., 2000; Cutler e Antin, 2001).

Praticamente todas as vias de administração de células-tronco foram utilizadas experimentalmente e, até o momento, não há um consenso na literatura em relação a qual seria a melhor, bem como não se sabe se haveria um número mínimo ou máximo de células a serem utilizadas (Otero et al., 2009). Ainda que o uso da terapia regenerativa nas doenças articulares de cães seja uma ideia inovadora, revolucionária e avançada, os reais benefícios clínicos permanecem desconhecidos, sendo necessários estudos que comprovem a sua efetividade e segurança.

Sabe-se que fatores de crescimento influenciam quimiotaxia, diferenciação, proliferação e atividade cinética de células ósseas, e, desta forma, regulam fisiologicamente a cicatrização do osso. Numerosos fatores de crescimento têm efeito estimulante sobre a cicatrização de um defeito ósseo, induzindo quimiotaxia, proliferação e diferenciação de osteoblastos e seus precursores (Sarkara et al., 2006). Nesse contexto, o objetivo deste trabalho foi avaliar a ação das células mononucleares autógenas, aplicadas intra-articularmente, em pacientes submetidos à correção cirúrgica intracapsular dos ligamentos cruzados cranial e caudal, 21 dias após a desmotomia.

\section{MATERIAL E MÉTODOS}

Foram utilizados 20 cães, machos e fêmeas, oriundos de biotério central. Os animais passaram por um período de adaptação de 30 dias, em gaiolas individuais. Durante esse período, todos foram desverminados, tiveram o membro pélvico direito radiografado e foram avaliados hematologicamente para a confirmação de suas adequadas condições de saúde. Foram separados em dois grupos, sendo um grupocontrole (GC) e um grupo- tratado (GT). Ambos foram distribuídos em dois períodos de biópsias, 50 (A) e 90 (B) dias. Os animais sofreram desmotomia dos ligamentos cruzados cranial e caudal unilaterais por artrotomia, conforme Müller et al. (2010), e aos 21 dias após a ruptura, todos foram tratados cirurgicamente pela técnica intracapsular de Müller et al. (2010). Os cães do GT, além do tratamento cirúrgico, receberam a fração total de células mononucleares autógenas da medula óssea, por aplicação intra-articular, ao término da correção cirúrgica. Para tanto, cada animal do GT foi submetido ao procedimento de colheita de MO, duas horas antes da correção, em ambiente cirúrgico, com toda a paramentação necessária a fim de promover um procedimento asséptico.

Utilizou-se, como protocolo anestésico, maleato de acepromazina, $0,05 \mathrm{mg} \mathrm{kg}^{-1}$, via intramuscular, associado ao cloridrato de morfina, $0,5 \mathrm{mg} \mathrm{kg} \mathrm{kg}^{-1}$, via intramuscular, como medicação pré-anestésica, seguida, após 15 minutos, de indução anestésica com propofol, $4 \mathrm{mg} \mathrm{kg}^{-1}$, via intravenosa. A manutenção da anestesia se deu com isoflurano vaporizado em circuito semiaberto com oxigênio. A oxacilina sódica, $30 \mathrm{mg} \mathrm{kg}^{-1}$, via intravenosa, foi utilizada como profilaxia antimicrobiana, 30 minutos antes do procedimento cirúrgico e baseou-se nos protocolos anti-inflamatório e analgésico pósoperatórios utilizados por Müller et al. (2010).

A MO foi colhida utilizando-se a agulha de Steis (11G X 3"), adotando-se, como sítios de colheita, ambos os fêmures e os úmeros, seguindo a 
técnica proposta por Müller et al. (2009). Colheu-se o volume total de MO de $10 \mathrm{~mL} \mathrm{~kg}^{-1}$, conforme proposto por Olsson et al. (2009), contudo optou-se por dividir esse volume aos quatro membros do animal, resultando em $2,5 \mathrm{~mL}$ $\mathrm{kg}^{-1}$ de MO em cada. Para isso, foi necessária apenas uma perfuração óssea em cada osso. O volume total de MO obtido foi filtrado em linha de $850 \mu \mathrm{m}, 500 \mu \mathrm{m}$ e $200 \mu \mathrm{m}$ da bolsa de transplante de MO para remoção de espículas ósseas e êmbolos gordurosos. A solução resultante foi acondicionada em bolsa de transporte para envio imediato ao laboratório.

Os primeiros $3 \mathrm{~mL}$ de medula colhidos diretamente do fêmur foram enviados para realização de mielograma. Lâminas foram confeccionadas por esfregaço, para análise complementar da atividade hematopoiética e morfológica das células da MO. As lâminas foram coradas por kit panótico rápido, composto de álcool fixador, corante eosinofílico e corante basofílico, e foram avaliadas de acordo com a relação mieloide e eritroide de normo, hipo ou hipercelular da MO, por microscopia de luz.

A separação das células da MO seguiu o protocolo descrito por Olsson et al. (2009), no qual, após a colheita, o volume foi centrifugado a 1600rpm (força centrípeta de $440 \mathrm{x} \mathrm{g}$ ) em tubos Falcon de $50 \mathrm{~mL}$ e isolado em gradiente de densidade Histopaque $1.077 \mathrm{~g} \mathrm{~mL}^{-1}(1: 1)$, de acordo com a técnica de Boyum (Boyum, 1968), mantendo-o à temperatura de $18-26^{\circ} \mathrm{C}$. O halo formado depois da centrifugação foi colhido entre as interfaces, lavados e centrifugados (cinco minutos; $440 \mathrm{x} \mathrm{g}$ ) três vezes em meio contendo solução salina $0,9 \%$, Dulbeco's Modified Eagle's Medium (DMEM), e soro sanguíneo autólogo estéril, com o intuito de remover os agregados celulares, obtendo-se, como produto final, o botão celular concentrado de células mononucleares -, padronizado em $1000 \mu \mathrm{L}$.

Uma pequena fração $(50 \mu \mathrm{L})$ de células mononucleares (CM) suspensas foi colhida para contagem manual da porcentagem e quantificação de CM. Testou-se a viabilidade celular (do botão celular) por método de exclusão com corante azul de Tripan 1\% (Melo et al., 2003) em lâmina de Neubauer, sendo considerada aceitável uma viabilidade acima de
$90 \%$ e um número mínimo de $2 \times 10^{6} \mathrm{~kg}^{-1}$ de $\mathrm{CM}$ $\mathrm{cm}^{2}$ (Suter et al., 2004).

Simultaneamente à separação das células, procedeu-se à correção cirúrgica do ligamento cruzado. Para tanto, adotou-se a técnica intracapsular de Müller et al. (2010), a qual utiliza implante sintético de polipropileno como substituto do ligamento cruzado cranial, fixado no fêmur e na tíbia por meio de orifícios ósseos. Ao final do procedimento, uma agulha, tamanho $25 \times 7$, foi introduzida na região articular para a aplicação das células. Cabe ressaltar que o procedimento cirúrgico foi programado para encerrar simultaneamente ao término do processamento das células.

As avaliações constaram de estudo radiológico, análise do líquido sinovial colhido no momento das biópsias, avaliações clínica, conforme escala de Penha et al. (2007), e microscópica do material colhido aos 50 e 90 dias pós-operatório, por meio dos métodos histoquímicos de hematoxilina-eosina , tricrômico de Masson e Von Kossa e imuno-histoquímica com marcação de CD34

A avaliação radiográfica constou de duas projeções, craniocaudal e mediolateral, nos momentos antes da ruptura do ligamento articulação sadia - e antes da biópsia - máximo período de permanência do implante, antes da sua remoção. Avaliou-se o crescimento de qualquer estrutura intra-articular, adotando-se como critério os graus: (0) sem alteração da superfície articular; (1) irregularidade da superfície articular; (2) saliência da superfície articular com leve projeção radiopaca; (3) saliência da superfície articular com acentuada projeção radiopaca.

Todos os animais foram submetidos à biópsia ao final dos períodos de observação, aos 50 ou 90 dias após a correção cirúrgica, e, para tanto, realizaram-se a artrotomia da articulação femorotibiopatelar e secção do implante com bisturi. As incisões para remoção do fragmento foram realizadas o mais próximo possível do fêmur e da tíbia, permitindo a avaliação de toda a porção do implante que manteve contato com o interior da articulação. Utilizaram-se quatro métodos para cada material biopsiado: $\mathrm{H} \& \mathrm{E}$, tricrômico de Masson, Von Kossa e marcação das células CD34 ${ }^{+}$. 
Ao final da biópsia de cada animal, quando se removeu o implante para análise, a articulação foi reestabilizada com o mesmo tipo de material, para que o cão fosse disponibilizado para adoção.

\section{RESULTADOS E DISCUSSÃO}

A opção por obter-se a MO dos quatro membros do animal baseou-se na afirmação de que o volume inicial colhido, após a perfuração de um osso longo, é, de fato, composto por MO. Entretanto, após "esgotar" a MO desse osso perfurado, inicia-se o refluxo de sangue periférico, devido ao íntimo contato da agulha com a artéria nutriente principal, localizada no espaço intramedular do osso (Brinker et al., 1999). Dessa forma, ao aumentar o número de ossos para colheita, aumentou-se também a quantidade efetiva de MO colhida. Como padronização da técnica, optou-se por colher um quarto do volume total em cada um dos quatro sítios, sendo esses o trocânter maior do fêmur e a cabeça do úmero (Müller et al., 2009), bilaterais. Pode-se afirmar que, neste trabalho, obteve-se a MO com mais facilidade, quando os úmeros foram o sítio de colheita. Dos 20 úmeros perfurados, em $12(60 \%)$ precisou-se apenas de um movimento de sucção com a seringa para se obter o volume desejado, enquanto no fêmur isso não ocorreu em nenhum dos 20 sítios. Esse dado é importante quando se pensa em velocidade do processo para evitar a morte celular (Olsson et al., 2009).

Com base na pesquisa de Olsson et al. (2009), a quantidade de MO colhida por animal foi de $10 \mathrm{~mL} \mathrm{~kg}^{-1}$ a qual, segundo Pizzo e Poplack (2005), em humanos, é a quantidade de medula ideal a ser colhida para que um número adequado de células-tronco mononucleares (CTM) seja alcançado. Gengozian (2000) indica como número ideal para a implantação ("pega") do enxerto $2 \times 10^{6}$ células com, pelo menos, $90 \%$ de células viáveis. Obteve-se, neste experimento, o número médio de $2,34 \times 10^{6}$ células $\mu \mathrm{L}^{-1}( \pm 1,75)$ com viabilidade média de $95,7 \%( \pm 2,35)$, o que se enquadra nos valores adequados para uma correta implantação.
Com relação ao local de administração da FCMO, mesmo não havendo consenso sobre a melhor via (Otero et al., 2009), estudos de Strauer e Kornowski (2003) e Anderson et al. (2005) demonstram ter sido encontrada maior quantidade de células quando estas foram administradas pela via intralesional. A partir desses dados, optou-se pela administração intraarticular das células, pois a via intravenosa, apesar de ser de mais fácil execução, possui o efeito de primeira passagem pulmonar e a necessidade de várias passagens circulatórias até que as células entrem em contato com a lesão. Esse fato pode diminuir significativamente a quantidade de células no tecido-alvo (Strauer e Kornowski, 2003).

$\mathrm{Na}$ avaliação radiográfica verificou-se que as alterações observadas nos animais eram oriundas dos orifícios ósseos por onde se passou o implante sintético. Dos 10 cães do grupocontrole, apenas um $(10 \%)$ apresentou grau 1 de irregularidade sobre o orifício da tíbia, não havendo sinais compatíveis com crepitação, dor ou claudicação do membro, conforme Penha et al. (2007).

Nos 10 animais do grupo-tratado, as alterações foram mais evidentes. Um cão $(10 \%)$ apresentou grau 1 de irregularidade, e outro apresentou grau 2. Nesses animais, a dor não esteve associada à flexão, crepitação ou claudicação, no momento das respectivas biópsias. Contudo, três cães (30\%) apresentaram grau 3 de irregularidade, ou seja, saliência a partir do orifício ósseo, com acentuada projeção radiopaca intra-articular (Fig. 1). Em dois desses animais, verificou-se dor discreta à flexão, permitindo que a articulação fosse manipulada, embora apresentassem sinais de desconforto durante o exame. Neles observouse crepitação moderada, intermitente, durante a flexão e extensão passivas, mas, curiosamente, eles não apresentaram claudicação (Penha et al., 2007). O fato de 50\% dos animais do grupotratado apresentarem algum crescimento intraarticular pressupõe a ação das células-tronco reconhecendo a lesão óssea iatropatogênica como uma importante fonte a ser reparada. Contudo, esse crescimento desordenado para o interior da articulação não é desejável. 


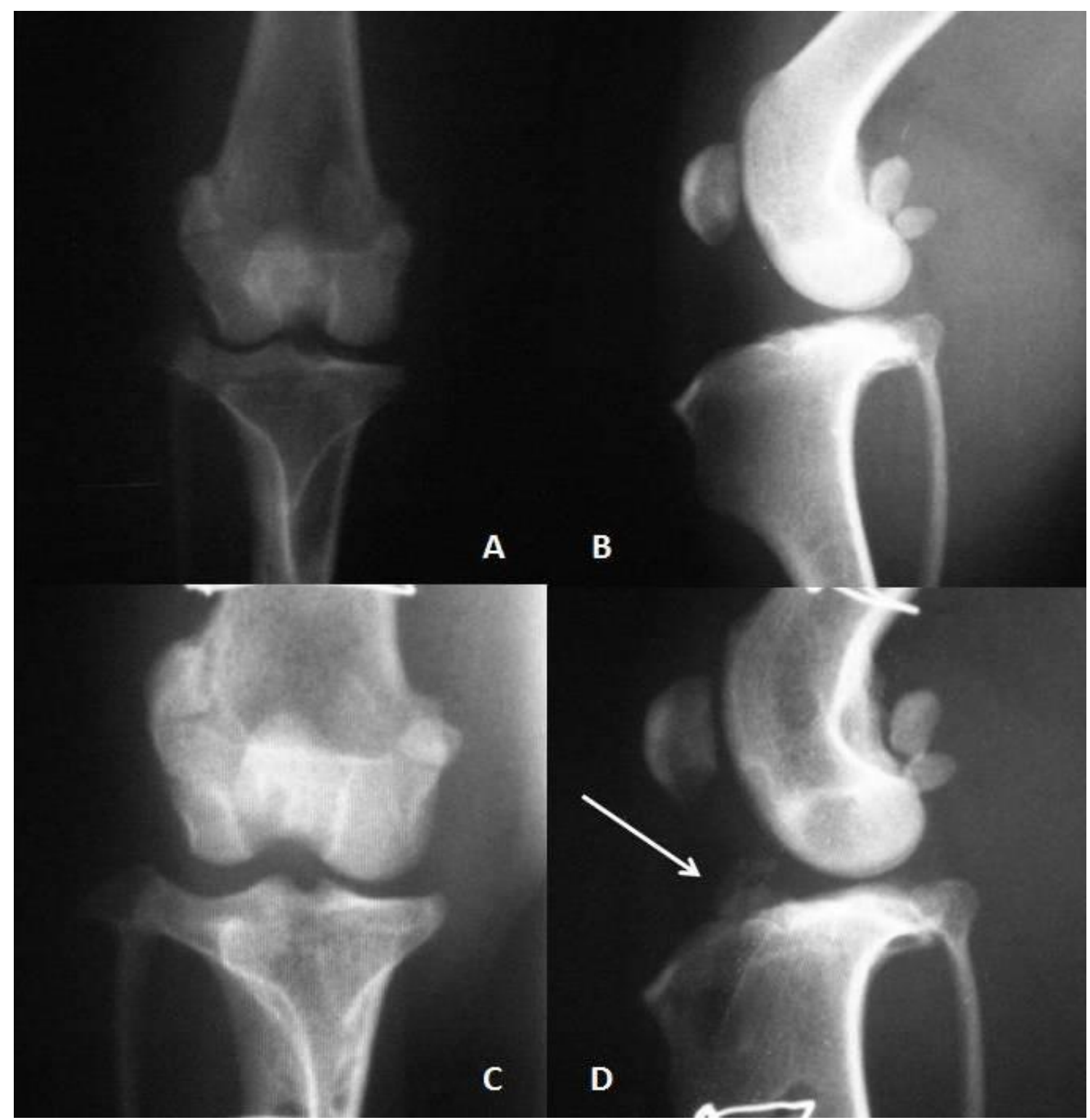

Figura 1. Imagem radiográfica do membro posterior direito de um cão do grupo-tratado, biopsiado aos 90 dias. Em (A), observa-se a incidência anteroposterior da articulação femorotibiopatelar, após desmotomia do ligamento cruzado cranial e caudal; e em (B), a imagem da incidência mediolateral no mesmo momento. As imagens (C) e (D) referem-se às mesmas incidências anteriores, porém após 90 dias da correção cirúrgica com a técnica proposta. A seta branca da figura (D) demonstra o crescimento radiopaco ocorrido a partir do orifício da tíbia, sobre o trajeto do implante sintético.

Neste estudo, o fator de estímulo para a diferenciação das células-tronco mononucleares em osteoblastos foi o próprio osso esponjoso trazido pelo implante, durante a passagem pelo orifício do fêmur (Kraus e Kirker-Head, 2006). Este material é comprovadamente uma substância osteoindutora, capaz de reparar lesões ósseas (Gonçalves et al., 1998; Ferrigno et al., 2007).
Ocorreu crescimento de tecido conjuntivo ao redor de todos os 20 implantes de polipropileno, o que permitiu considerar um reforço extra à resistência e durabilidade do ligamento sintético. À coloração de Hematoxilina-Eosina, este tecido conjuntivo mostrou-se denso e maduro, apresentando-se intimamente entrelaçado à trama do implante. 
Em três amostras, identificou-se presença de medula óssea funcional - capaz de gerar células sanguíneas - no material colhido, em animais do GT. Considerando que a técnica cirúrgica utilizada para a reconstrução do ligamento cruzado perfurou tanto o fêmur quanto a tíbia do animal, pode-se supor que o contato da articulação com o osso esponjoso das epífises perfuradas foi um estímulo muito forte para a diferenciação das células-tronco aplicadas no local.

$\mathrm{Na}$ imuno-histoquímica, marcou-se o antígeno de superfície CD34 com o objetivo de se identificarem as células-tronco mononucleares presentes no sítio operatório. Para surpresa dos pesquisadores, todas as 20 amostras apresentaram células $\mathrm{CD} 34^{+}$, o que demonstra a presença de células-tronco hematopoiéticas no implante de todos os animais, e em quantidades semelhantes.

O fato de haver células $\mathrm{CD} 34^{+}$nos cães do GC pode ter duas explicações. A primeira é a quimiotaxia de células-tronco estocadas no organismo, para o local da lesão, chamada de "homing" (Verfaillie, 2002). Entretanto, suspeita-se que esse achado possa ter outra explicação. Ao se perfurar o fêmur e a tíbia, para fixar o implante, pode ter ocorrido o extravasamento da MO para o espaço intraarticular, o que permitiu o contato dessa com o implante - trama de polipropileno em quatro camadas -, e, assim, a medula óssea teria funcionado como fornecedora de células-tronco durante a formação do tecido conjuntivo. Isso ocorreu ao longo do período avaliado, e explica, inclusive, o número semelhante de células marcadas entre os grupos.

As fibras coradas pelo tricrômico de Masson eram de cor azul e vermelha, demonstrando que havia maturação normal do tecido fibroso. À coloração de Von Kossa, evidenciou-se presença de depósitos de cálcio em 16 amostras (80\%), sendo elas nove $(45 \%)$ do GT e sete $(35 \%)$ do GC.

$\mathrm{Na}$ análise do líquido sinovial, foram verificadas alterações nos aspectos físico, químico e citológico. A coloração rosada e a turbidez foram evidenciadas em sete das 12 amostras analisadas visualmente. Esses resultados apontam para um possível processo inflamatório e/ou degenerativo, como citam De Biasi et al. (2001).

A concentração proteica total no líquido manteve-se elevada em todas as amostras, com média de 4,5g/dL, comparada com valores normais, que variam de 2,0 a 2,5g/dL (Perman, 1980; Lipowitz, 1985). De acordo com Fernandez et al. (1983), os valores de proteína apresentam-se elevados em casos de artropatia inflamatória devido ao aumento da permeabilidade vascular.

Neste estudo, a contagem total de células nucleadas variou de 1000 a $4800 / \mu \mathrm{L}$, com média de 1500 células/ $\mu \mathrm{L}$, sendo que essa característica em líquidos normais varia de 250 a 3000/ $\mu \mathrm{L}$ (Brinker et al., 1999). Na avaliação citológica diferencial, foram visualizadas células mononucleares, macrófagos, monócitos; células mesoteliais, sinoviócitos, plasmócitos, linfócitos; e células polimorfonucleares, neutrófilos e eosinófilos. A porcentagem de mononucleares pode chegar a $100 \%$ e a de polimorfonucleares mantém-se próxima de zero (Johnson e Johnson, 1993).

$\mathrm{Na}$ contagem diferencial, uma amostra apresentou celularidade típica de doença inflamatória aguda, contendo $90 \%$ de neutrófilos segmentados. Entretanto, o restante das amostras manteve padrão crônico típico de processo degenerativo, com celularidade mononuclear variando de 65 a $100 \%$ e predominância de macrófagos e linfócitos (Bennett et al., 1988; Johnson e Johnson, 1993; Wilkins, 1993). Outro aspecto observado foi reatividade de células mesoteliais, linfócitos e macrófagos, o que indica reação articular degenerativa. De acordo com Bennett et al. (1988) e Johnson e Johnson (1993), os dados encontrados na análise do líquido sinovial são compatíveis com processo degenerativo de natureza não inflamatória. Essa situação pode advir do fato de que o modelo experimental aqui utilizado fez uso de apenas um ligamento sintético para substituir os ligamentos cruzados cranial e caudal. Essa técnica é capaz de estabilizar funcionalmente a articulação, contudo Müller et al. (2010) afirmam que algum grau de instabilidade permanecerá após a cirurgia e, portanto, não impedirá a progressão da DAD. 


\section{CONCLUSÕES}

Para o modelo experimental proposto, não se recomenda o uso da fração total de células mononucleares, pois estas podem atuar no reparo da lesão óssea e induzir crescimento ósseo intra-articular. Trabalhos experimentais com articulações, que envolvam células-tronco, devem evitar modelos cujo foco de lesão mantenha contato direto com a medula óssea, pois isto torna incerta a origem das célulastronco encontradas nas respectivas biópsias. Conclui-se ainda que, apesar de não ter havido diferença clínica entre o grupo- tratado e o grupo-controle e de a avaliação radiográfica ter apresentado resultados indesejáveis, a fração total de células mononucleares, de aplicação intra-articular, foi capaz de induzir o crescimento de medula óssea funcional junto ao implante.

\section{COMITÊ DE ÉTICA}

Este estudo foi aprovado pelo Comitê em Ética em Pesquisa com animais da Universidade Federal de Santa Maria, sob o $\mathrm{n}^{\mathrm{o}}$ 23081.003653/2008-59, e seguiu os princípios éticos do Colégio Brasileiro de Experimentação Animal (COBEA).

\section{REFERÊNCIAS}

ANDERSON, D.; RISBUD, M.V.; SHAPIRO, I.M. et al. Cell-based therapy for disc repair. The Spine J., v.5, p.297-303, 2005.

BENNETT, D.; TENNANT, B.; LEWIS, D.G. et al. A reapraisal of anterior cruciate ligament disease in the dog. J. Small Anim. Practice, v.29, p.275-297, 1988.

BOYUM, A. Separation of leukocytes rom blood and bone marrow. Introduction. Scand. J. Clin. Lab. Investigation Supplement, v.97, p.7, 1968.

BRINKER, W.O.; PIERMATTEI, D.L.; FLO, G.L. Manual de ortopedia e tratamento das fraturas dos pequenos animais. São Paulo: Manole, A articulação fêmoro-tíbio-patelar (joelho). 1999. Cap.17, p.480-537.

CUTLER, C.; ANTIN, J.H. Peripheral blood stem cells for allogeneic transplantation: a review. Stem Cells, v.19, p.108-117, 2001.
DE BIASI, F.; RAHAL, S.C.; LOPES,R.S. et al. Alterações no líquido sinovial do joelho de cães com osteoartrite induzida pelo modelo Pond e Nuki. Arq. Bras. Med. Vet. Zootec., v.53, p.563567, 2001.

FERNANDEZ, F.R.; GRINDEN, C.B.; LIPOWITZ, A.J. et al. Synovial fluid analysis: Preparation of smears for cytologic examination of canine synovial fluid. J. Amer. Anim. Hosp. Associat., v.19, p.727-734, 1983.

FERRIGNO, C.R.A.; NINA, M.I.D.; FANTONI, D.T. Estudo comparativo entre as osteossínteses com placas e osteossínteses com placas associadas a enxertos de proteína morfogenética óssea (Gen-Tech) em fraturas distais de rádioulna em cães com menos de 6 quilos. Pesq. Vet. Bras., v.27, p.65-69, 2007.

GALLACHER, L.; MURDOCH, B.; KARANU, W.D. et al. Identification of novel circulating human embryonic blood stem cells. Blood, v.96, p.1740-1747, 2000 .

GENGOZIAN, N. Identification and isotation of hematopoietic progenitors. In: FELDMAN, B.F. et al. Scham's veterinary hematology. Philadelphia: Williams \& Wilkins, 2000. cap.16, p.91-96.

GONÇALVES, E.A.L.; GUIMARÃES, S.A.C.; GARCIA, R.B. Proteínas morfogenéticas ósseas: terapêutica molecular no processo de reparo tecidual. Rev. Odontol. Univ., v.12, p.299-304, 1998. Disponível em: <http://www.scielo.br/scielo.php?script=sci_artte xt\&pid=S010306631998000300018\&lng=en\&nrm=iso>. Acessado em: $20 \mathrm{dez} 2007$.

JOHNSON, J.M.; JOHNSON, A.L. Cranial cruciate ligament rupture. Pathogenesis, dianosis and postoperative rehabilitation. Vet. Clin. North Am.: Small Anim. Pract., v.23, p.717-733, 1993.

KRAUS, K.H.; KIRKER-HEAD, C. Mesenchymal stem cells and bone regeneration. Vet. Surg., v.32, p.232-242, 2006.

LIPOWITZ, A.J. Synovial fluid. In: NEWTON, C.D., NUNAMARKER, D.M. Textbook of small animal orthopaedics. Philadelphia: Lippincott, 1985. p.1015-1028. 
MELO, D.F.; SELL, A.M.; LOPES, C.M. et al. Viabilidade das células mononucleares de sangue periférico humano em diferentes meios de estocagem de dentes avulsionados. Acta Scientiarum Health Scie., v.25, p.69-74, 2003.

MOTA, A.C.A.; SOARES, M.P.B.; SANTOS, R.R. Uso de terapia regenerativa com célulastronco da medula óssea em doenças cardiovasculares - perspectiva do hematologista. Rev. Bras. Hematol. Hemoterapia, v.27, p.126132, 2005

MÜLLER, D.C.M.; PIPPI, N.L.; BASSO, P.C. et al. Técnicas e sítios de coleta de medula óssea em cães e gatos. Cienc. Rural, v.39, p.22432251, 2009.

MÜLLER, D.C.M.; PIPPI, N.L.; BASSO, P.C. et al. Implante sintético como estabilizador articular, após desmotomia dos ligamentos cruzados de cães: proposição de técnica. Cienc. Rural, v.40, p.1327-1334, 2010.

OLSSON, D.C.; PIPPI, N.L.; MARTINS, D.B. et al. Colheita de medula óssea em cães: modelo para obtenção da fração total de células mononucleares. Cienc. Rural, v.39, p.141-147, 2009.

OTERO R.M.; GUIMARÃES, A.G.; COELHO, P.M.P. et al. Terapia celular no acidente vascular cerebral. Rev. Bras. hematol. e hemoterapia, v.31, p.99-103, 2009.

PENHA, E.M.; REZENDE, C.M.F.; MELO, E.G. et al. Pós-operatório tardio da substituição do ligamento cruzado cranial no cão. Arq. Bras. Med. Vet. Zootec., v.59, p.1184-1193, 2007.
PERMAN, V. Synovial fluid. In: KANEKO, J.J. Clinical biochemistry of domestic animals. 3.ed. New York: Academic, 1980. p.749-83.

PIZZO, P.A.; POPLACK, D.G. Principles and practice of pediatric oncology. Filadelfia: Lippincott Williams \& Wilkins. 2005. 1780 p.

SARKARA, M.R.; AUGAT, P.; SHEFELBINE, S.J. et al. Bone formation in a long bone defect model using a platelet-rich plasma-loaded collagen scaffold. Biomaterials, v.27, p.18171823, 2006.

SOUZA, L.C.G.; CARVALHO, K.A.T.; REBELATTO, C. et al. A comparação entre o transplante de células tronco mononucleares e mesenquimais no infarto do miocárdio. Braz. J. Cardiovascular Surg., v.20, p.270-278, 2005.

STRAUER, B.E.; KORNOWSKI, R. Stem cell therapy in perspective. Circulation, v.107, p.929934, 2003.

SUTER, S.E.; GOUTHRO, T.A.; MCSWEENEY, P.A. et al. Isolation and characterization of pediatric canine bone marrow CD34+cells. Vet. Immunol. Immunopathol., v.101, p.31-47, 2004.

VERFAILIE, C.M. Hematopoietic stem cells for transplantation. Nature Immunol., v.3, p.314317, 2002.

WILKINS, R.J. Joint fluid analysis. In: BOJRAB, M.J. Disease mechanisms in small animal surgery. 2.ed. Philadelphia: Lea \& Febiger, 1993. p.705-710. 